\title{
Enhanced model protein adsorption of nanoparticulate hydroxyapatite thin films on silk sericin and fibroin surfaces
}

\author{
Selçuk Özcan $\mathbb{B}^{1} \cdot$ Muhsin Çiftçioğlu²
}

Received: 2 April 2021 / Accepted: 3 December 2021 / Published online: 23 December 2021

(c) The Author(s) 2021

\begin{abstract}
Hydroxyapatite coated metallic implants favorably combine the required biocompatibility with the mechanical properties. As an alternative to the industrial coating method of plasma spraying with inherently potential deleterious effects, sol-gel methods have attracted much attention. In this study, the effects of intermediate silk fibroin and silk sericin layers on the protein adsorption capacity of hydroxyapatite films formed by a particulate sol-gel method were determined experimentally. The preparation of the layered silk protein/hydroxyapatite structures on glass substrates, and the effects of the underlying silk proteins on the topography of the hydroxyapatite coatings were described. The topography of the hydroxyapatite layer fabricated on the silk sericin was such that the hydroxyapatite particles were oriented forming an oriented crystalline surface. The model protein (bovine serum albumin) adsorption increased to $2.62 \mu \mathrm{g} / \mathrm{cm}^{2}$ on the latter surface as compared to $1.37 \mu \mathrm{g} / \mathrm{cm}^{2}$ of hydroxyapatite on glass without an intermediate silk sericin layer.
\end{abstract}

\section{Graphical Abstract}

The BSA adsorption on glass (blank), glass/c-HAp, glass/m-HAp, glass/sericin/c-HAp, and glass/sericin/m-HAp substrates, reported as decrease in BSA concentration versus contact time.

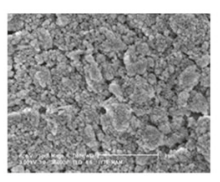

Glass/m-HAp
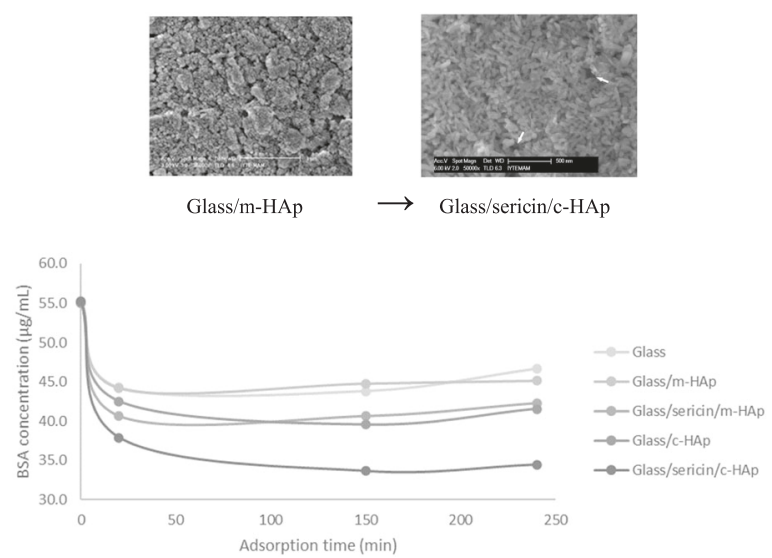

$\rightarrow$ Glass/sericin/c-HAp

\section{Introduction}

The formation of hydroxyapatite in vivo as the mineral constituent of bone and teeth tissue is closely related to the physiology of calcium and phosphate metabolism in vertebrates. The intricate hormonal control (parathyroid hormone and calcitonin with the combined effect of vitamin $\mathrm{D}_{3}$ ) mechanisms of osteoblastic and osteoclastic activities, including the feedback control of calcium and phosphate extracellular fluid levels, regulate the deposition and resorption of calcium phosphate $(\mathrm{CaP})$ compounds in the
Selçuk Özcan

selcuk.ozcan@bilecik.edu.tr

1 Department of Industrial Engineering, Bilecik Şeyh Edebali University, Bilecik, Turkey

2 Department of Chemical Engineering, Izmir Institute of Technology, Urla, Izmir, Turkey 
bone [1]. The embodiment of hard tissue implants to the host bone tissue is achieved through morphological fixation, osteoconduction, osseointegration, chemical adhesion, or time regulated resorption, with healing accelerated osteoinductively, governed by the closely related biological and chemical processes. The intended permanent or transitory anchorage of the implant in the living tissue with a minimal foreign body reaction, for proper biofunctioning, and without premature failure, is engineered by material development, design, and strict quality assured manufacturing [2].

Biocompatible mineral coatings of $\mathrm{CaP}$ allow a variety of materials to be employed as in vivo hard tissue implants $[3,4]$. They act as local scaffolds for enhanced osteoconduction by osteogenic cell migration, proliferation, and differentiation on the implant surface (osteoinduction) resulting in ingrowth of the surrounding hard tissue. Hydroxyapatite (HAp), $\mathrm{Ca}_{10}\left(\mathrm{PO}_{4}\right)_{6}(\mathrm{OH})_{2}$, has been experimentally confirmed to be one of the best implant coating materials for post-operative fast bone apposition and cementless mechanical fixation based on the concerted dynamic resorption-precipitation-bone substitution in vivo processes [5]. Plasma spraying of HAp is the only method commercially approved by the U.S. Food and Drug Administration (FDA) for biomedical coatings on implants so far [6]. However, there is a general tendency to develop new routes for hydroxyapatite coatings on implant materials due to the fact that coatings produced by the plasma spraying have a number of disadvantages, namely, inhomogeneous chemical composition and crystallinity, formation of in vivo fast dissolving unfavorable phases ( $\alpha$-tricalcium phosphate, tetracalcium phosphate, oxyhydroxyapatite, calcium oxide, and amorphous phases), thermal and amorphous to crystalline phase transformation stress cracking, and delamination or even detachment of the coating layer [7-10]. There exist active research efforts to overcome the adverse effects $[11,12]$. Hydroxyapatite film coatings prepared by sol-gel methods have attracted much attention due to the inherent advantages of being chemically and physically homogeneous and pure, capability of tailoring chemical composition, porosity, pore size and surface roughness, besides the relative simplicity of the method [13-15]. Nevertheless, some of the HAp coatings achieved by the sol-gel techniques, especially, when HAp forms in-situ during the coating process, yields an amorphous or poorly crystalline HAp layer that may suffer the drawbacks due to the amorphous HAp phase as in plasma spraying [6].

The favorable interactions between hydroxyapatite, and silk fibroin and sericin in the biomimetic nucleation and crystal growth of hydroxyapatite deposits, were experimentally observed [16, 17]. The aspartate, arginine, glutamate residues are arranged in polar clusters in the $\beta$-sheet structure of fibroin (characterized by the repetitive primary sequence of amino acids of a long chain of $350 \mathrm{kDa}$, connected to a shorter chain by disulfide linkage [18]), inducing a surface potential distribution due to the hydroxyl, carboxyl, and carbonyl groups, that have an affinity for calcium ions, providing local concentrations of $\mathrm{Ca}^{2+}$ leading to nucleation of HAp crystals. HAp is deposited in the form of tiny crystals on fibroin due to the regular surface arrangement of nucleation sites distributed on a molecular scale. In the $\beta$-sheet structure of sericin (molecular weight 20-400 kDa [19]), $10 \%$ of the carboxyl groups are arranged perpendicular to the plane of the sheet, providing a periodic distribution of surface electrostatic potential sites which induces electrostatic affinity for $\mathrm{Ca}^{2+}$ ions leading to HAp nucleation and crystal growth.

Fracture or peri-implant healing involves interactions between the critical physical, molecular, and cellular elements inducing the sequence of events: potentially osteogenic cell recruitment, attachment, expansion, differentiation, and bone tissue generation. Cytokines and bone morphogenetic proteins (BMPs) from the disrupted matrix, and from degranulation of platelets in the hemorrhage zone signal and guide the marrow derived osteogenic cell populations including vascular pericytes, stromal cells and mesenchymal stem cells (MSCs) to migrate to the damaged site. MSCs are converted to preosteogenitor cells on the site which then transform into osteoblastic, chondroblastic, or fibroblastic differentiated cell lineages. The technology to use $\mathrm{CaP}$ compound coatings as BMPs carrier is under development by imparting enhanced affinity between hydroxyapatite and proteins [2, 20]. In many of these studies bovine serum albumin (BSA) was used as model protein to mimic the behavior of BMPs [21]. The surface topography of the hydroxyapatite was shown to be as important as the chemistry for protein adsorption [22, 23].

In this study, hydroxyapatite thin film implant surfaces were prepared by a particulate sol route. A variety of particle dispersion techniques were used to prepare HAp colloidal suspensions. Preparation of thin films of HAp with the colloidal suspensions on bioinert glass surfaces by the dip coating method was investigated. The microstructure of the films was characterized by scanning electron microscope (SEM), atomic force microscope (AFM), X-ray diffraction (XRD) and Fourier transform infra-red spectroscopy (FTIR), while the results for the latter two were presented elsewhere [24]. The particulate sol-gel method utilizing the commercially pre-synthesized fully crystalline HAp powder made sure that the HAp layer was crystalline and remained crystalline after the heat treatment [24]. The effects of the intermediate silk fibroin and silk sericin coatings on the formation and surface topography of HAp films were determined. The model protein (BSA) 
adsorption capabilities of the various hydroxyapatite surfaces were investigated comparatively.

\section{Experimental}

\subsection{The hydroxyapatite powder size reduction}

The commercially available hydroxyapatite powder (cHAp; $\mathrm{Ca}_{10}(\mathrm{PO} 4)_{6}(\mathrm{OH})_{2}$, SIGMA, C 567-500 G, FW = 1004.6, $\left.\mathrm{mp}=1670{ }^{\circ} \mathrm{C}, \mathrm{d}=3.14 \mathrm{~g} / \mathrm{cm}^{3}\right)$ was used for thin film preparations, as received, and after dry ball milling in a $250 \mathrm{ml}$ tungsten-carbide jar revolved in a gyrator. The grinding medium comprised 30 pieces tungsten-carbide balls of $1 \mathrm{~cm}$ in diameter. Each load for milling consisted of $15 \mathrm{~g}$ of c-HAp. The milling was carried out for a maximum of $120 \mathrm{~min}$ at $400 \mathrm{rpm}$ with intermittent $15 \mathrm{~min}$ grinding and cooling periods (from this point on the 120 min dry milled powder will be denoted as m-HAp powder; $m$ for dry milled). The details of the particle size distribution measurements and the methods for dispersion in deionized water were given elsewhere [24]. Shortly, the particle size distribution measurements were carried out with the X-ray scattering sedigraph (Micromeritics Sedigraph 5100), and the measurement concentration of the suspensions was $0.02 \mathrm{~g} / \mathrm{mL}(1.0 \mathrm{~g}$ of solids was dispersed in $50 \mathrm{ml}$ with deionized water). c-HAp powder was dispersed in deionized water by various methods (and also combinations of methods) at various solids loadings with hydropalate $(2 \mathrm{w} / \mathrm{w}$ $\%$; sodium di-isooctylsulfosuccinate, $\mathrm{C}_{20} \mathrm{H}_{38} \mathrm{O}_{7} \mathrm{~S}$, MW $=$ 422.58, Henkel) as dispersant. The dispersion methods were ultrasound treatment, wet ball milling, fast mixing in baffled blender, suspension quenching in liquid nitrogen, thermal shock by water quenching of heated powder.

\subsection{The $\mathrm{pH}$, and organic dispersant ratio}

The optimum dispersion of c-HAp, and m-HAp powder suspensions were determined by the zeta sizer (Malvern Instruments Ltd. 3000 HSA). Stock suspensions of c-HAp and m-HAp powders were prepared by adding $10 \mathrm{~g}$ of powder into $47 \mathrm{~g}$ of deionized water. The organic dispersant, hydropalate 64 , was added at various amounts $(0-0.36 \mathrm{~g}$ or 6 drops). The deagglomeration was carried out by wet ball milling in glass jars with a grinding medium of zirconia balls ( $30 \mathrm{~g}$ of $\varnothing 5 \mathrm{~mm}$, and $15 \mathrm{~g}$ of $\varnothing 3 \mathrm{~mm}$ ) for $2 \mathrm{~h}$ at $200 \mathrm{rpm}$. The stock suspension was then diluted to a solid content convenient for measurement in the zeta sizer. $0.2 \mathrm{ml}$ of the stock solution was first diluted to $10 \mathrm{ml}$. The diluted suspension was ultrasonicated for $30 \mathrm{~min}$, and $1.0 \mathrm{ml}$ of it was diluted to $20 \mathrm{ml}$ in a beaker that corresponds to an overall 1000-fold dilution. The final solid content was approximately $0.17 \mathrm{~g} / \mathrm{L}$. Before the measurements, the $\mathrm{pH}$ of the suspension in the beaker was adjusted in the range from 7 to 11 by $0.1 \mathrm{~N} \mathrm{NH}_{4} \mathrm{OH}$ addition, and ultrasonicated for an additional $15 \mathrm{~min}$ while stirring.

\subsection{Preparation of hydroxyapatite/silk protein thin films by dip coating}

Thin film coatings of hydroxyapatite were achieved by dip coating of bioinert glass slide substrates in dispersed suspensions. The glass slides were cleaned by detergent solution, ethyl alcohol, and acetone subsequently. $15 \mathrm{w} / \mathrm{w} \%$ aqueous suspensions of c-HAp, and m-HAp powders were prepared in deionized water. The steric dispersant hydropalate 64 was added in the ratio $2.4 \mathrm{w} \%$ of the total solids. The $\mathrm{pH}$ of the c-HAp, and m-HAp suspensions were adjusted to 9.8-10.0, and 9.4-9.6 (with $1.0 \mathrm{~N} \mathrm{NH}_{4} \mathrm{OH}$ ), respectively. These $50 \mathrm{ml}$ suspensions were ultrasonically treated $(30 \mathrm{kHz})$ while stirring for $30 \mathrm{~min}$, followed by wet ball milling in $100 \mathrm{ml}$ jars with a grinding medium of zirconia balls ( $30 \mathrm{~g}$ of $\varnothing 5 \mathrm{~mm}$, and $15 \mathrm{~g}$ of $\varnothing 3 \mathrm{~mm}$ ) for $2 \mathrm{~h}$ at $200 \mathrm{rpm}$. Finally, the suspensions were ultrasonically treated for $2 \mathrm{hr}$ before dip coating.

The bioinert glass substrates were dip coated in the c-HAp and m-HAp suspensions at $25^{\circ} \mathrm{C}$ with a retraction rate of $100 \mathrm{~mm} / \mathrm{min}$. The substrates were coated up to 5 layers with $30 \mathrm{~min}$ of ambient drying in between. Some of the thin films on glass substrates were heat treated at $560{ }^{\circ} \mathrm{C}$, for $30 \mathrm{~min}$ with a heating ramp rate of $15^{\circ} \mathrm{C} / \mathrm{min}$. The film thicknesses were measured with Mitutoyo SJ-301 surface roughness tester in the primary profile mode, generating a length-depth profile of the film scratched with a 85 shore A hard rubber.

The sericin and fibrion film coatings on glass substrates were prepared by dip coating in the sericin and fibroin solutions with a retraction rate of $100 \mathrm{~mm} / \mathrm{min}$ at ambient temperature $\left(25^{\circ} \mathrm{C}\right)$. The preparations of sericin and fibroin solutions are described below. The substrates were coated with three layers of sericin and fibroin, with $30 \mathrm{~min}$ of ambient drying between coatings. The sericin and fibroin coated glass slides were than coated with c-HAp and m-HAp in the same way described above.

The sericin solution was prepared by dissolving $4.2 \mathrm{~g}$ of commercial sericin (Silk Biochemical Co. Ltd., ref: 46-3108 ) in $48 \mathrm{ml}$ of deionized water. Silk fibroin solutions were prepared by the subsequent processes of degumming and dissolution of the raw silk (Silk Biochemical Co. Ltd., ref no: biosilk 04056). The degumming was carried out by boiling in $0.05 \%$ aqueous $\mathrm{Na}_{2} \mathrm{CO}_{3}$ solution $(2.0 \mathrm{~g}$ of silk in $100 \mathrm{~mL}$ solution) for $30 \mathrm{~min}$. The degummed silk was washed with deionized water and left over for drying at ambient conditions. $1.2 \mathrm{~g}$ of the degummed silk was further treated with 20 times of Ajisawa's reagent $\left(24 \mathrm{~mL}\right.$ of $\mathrm{CaCl}_{2} /$ ethanol/water: 111/92/144 by weight) in a $250 \mathrm{~mL}$ Schott 
bottle by stirring at $78^{\circ} \mathrm{C}$ for $2 \mathrm{~h}$ to obtain a clear solution [25]. Higher concentrations were avoided due to the gelation tendency during the following dialysis step. The fibroin solution was dialyzed in cellulose dialysis tubing against deionized water at $4{ }^{\circ} \mathrm{C}$ by frequent change of dialysis water for the removal of $\mathrm{CaCl}_{2}$ and other neutral salts until tested negative for $\mathrm{AgCl}$ precipitation by $\mathrm{AgNO}_{3}$ ( $\sim 3$ days). The treated cellulose tubings were rated to retain protein molecules of over $12,000 \mathrm{~g} / \mathrm{mol}$. The silk fibroin solution (1-2\% $\mathrm{w} / \mathrm{v}$ ) in the dialysis tubings was filtered (Filtrak 389 filter paper) and concentrated to $\sim 10 \% \mathrm{w} / \mathrm{v}$ by a rotary vacuum evaporator at $30^{\circ} \mathrm{C}, 30 \mathrm{rpm}$.

\subsection{Bovine serum albumin and collagen adsorption on thin films}

The adsorption behavior of bovine serum albumin (BSA, the adsorbate) on the hydroxyapatite thin films (c-HAp, and m-HAp) was investigated. The quantity of BSA adsorbed on the HAp surfaces was determined as a function of contact time. The adsorbent substrates were bioinert glass, glass/c-HAp, glass/m-HAp, glass/sericin/c-HAp, and glass/ sericin/m-HAp.

The bovine serum albumin (BSA; SIGMA CAS 904846-8, A2153-100G, Albumin from bovine serum, min. $96 \%$, electrophoresis) solution was prepared in $100 \mathrm{mM}$ PBS (phosphate buffer saline). $50 \mathrm{mg} / \mathrm{L}$ solution was prepared and diluted in two steps to $0.050 \mathrm{mg} / \mathrm{mL}(50 \mu \mathrm{g} / \mathrm{mL})$. All dilutions were carried out by $100 \mathrm{mM}$ PBS solution.

The adsorption was carried out in $100 \mathrm{~mL}$ beakers in the incubator kept at $37^{\circ} \mathrm{C}$, and $60 \mathrm{rpm}$. 5 substrates were placed in each beaker to form $59.8 \mathrm{~cm}^{2}$ adsorption area. The BSA concentration was measured as a function of contact time. The BSA concentration was measured by an HPLC size exclusion method. The column used was ZORBAX bio series GF-250 (LX14004 PN 884973.901 max pressure 350 bar). The mobile phase used was $100 \mathrm{mM}$ PBS solution. The UV-vis detector module set at $210 \mathrm{~nm}$ wavelength. The $50 \mu \mathrm{L}$ of the BSA solution sample was manually injected. Two peaks were obtained for BSA; the small peak belonged to the dimer of BSA, and a major peak with the retention times of $4.55 \mathrm{~min}$ and $4.96 \mathrm{~min}$, respectively. The results were reported as the corresponding total area of the two peaks. The calibration curve was formed for a range of concentrations from 0.01 to $0.10 \mathrm{mg} / \mathrm{L}$.

The SEM images of the thin films were obtained by Philips XL-30S FEG. For AFM imaging (Digital Instruments MMSPM Nanoscope IV was used in the tapping mode with rectangular silicon nitride cantilever, and silicon tip to obtain the 3-dimensional surface topology, and phase information of the film surfaces), BSA solution, and collagen type I aqueous suspension were prepared in $10 \mathrm{mM}$ PBS (phosphate buffer saline). The concentration of BSA was adjusted to $1.0 \mathrm{mg} / \mathrm{mL}$ (total volume $25 \mathrm{ml}$ ). Collagen type I (SIGMA C-9879 $1 \mathrm{~g}$, Type I, Insoluble, from Bovine Achilles Tendon, 9007-34-5) was water insoluble, and it was dispersed as a homogeneous suspension in ultrasound bath. The concentration was $0.1 \mathrm{mg} / \mathrm{mL}$ (total volume $25 \mathrm{ml}$ ). The glass, glass/sericin, glass/fibroin, glass/c-HAp, glass/m-HAp, glass/sericin/c-HAp, glass/sericin/m-HAp, glass/fibroin/c-HAp, glass/fibroin/m-HAp substrates were prepared by dip coating as described previously, and the samples were cut into maximum $1 \times 1 \mathrm{~cm}$ size suitable for AFM measurements. Two samples of each type of coating were placed separately in the BSA solution and the collagen type I suspensions perpendicularly to avoid any gravitational settling on the films. The samples were kept in the suspensions for $4 \mathrm{hr}$. The samples were rinsed with deionized water to sweep away the loosely bound BSA particles and collagen fibers and left over for ambient drying.

\section{Results}

\subsection{Particulate sol route hydroxyapatite/silk protein thin film surface interactions}

As a result of the dry ball milling the tapped density increased from $0.44 \mathrm{~g} / \mathrm{cm}^{3}$ (c-HAp) to $0.96 \mathrm{~g} / \mathrm{cm}^{3}$ (m-HAp). The commercial powder consisted of rod like particles of $150-250 \mathrm{~nm}$ in length and $50-80 \mathrm{~nm}$ in diameter, while the dry milled powder consisted of equiaxed particles of $40-100 \mathrm{~nm}$ in diameter. The details of hydroxyapatite powder characterization, dispersion, and coating were given elsewhere [24]. The coatings of HAp were prepared on bioinert glass substrates by dip coating the SEM pictures of which as can be seen in Fig. 1. The aqueous suspensions of HAp contained $2.4 \mathrm{w} \%$ hydropalate 64 as the dispersant, and at $\mathrm{pH}$ values of 10.2 for $\mathrm{c}-\mathrm{HAp}$ and 9.4 for m-HAp, with $15 \mathrm{w} \%$ solids content of the suspensions. The maximum agglomerate sizes were determined to be $2 \mu \mathrm{m}$ for the coatings of c-HAp, and $5 \mu \mathrm{m}$ for the coatings of the m-HAp. The agglomerates of the sizes from $450 \mathrm{~nm}$ to $1 \mu \mathrm{m}$ were most abundant for both type of coatings. The agglomerates larger in number and size in the m-HAp coatings, proved to be an indication of the higher agglomeration tendency, during the drying/particle compaction step of the thin film formation, with increasing surface area, and hence, lower zeta potential of the crushed particles in the suspensions [24]. The thicknesses of the thin films prepared with the c-HAp powder were determined to be in the range $450-650 \mathrm{~nm}$, while the ones with the m-HAp were in the range $500-750 \mathrm{~nm}$. The effect of heat treatment, at $560^{\circ} \mathrm{C}$, for $30 \mathrm{~min}$ with a heating ramp rate of $15^{\circ} \mathrm{C} / \mathrm{min}$, on the thin films prepared was investigated. There were no cracks forming de novo, or propagating. Nevertheless, the onset of 

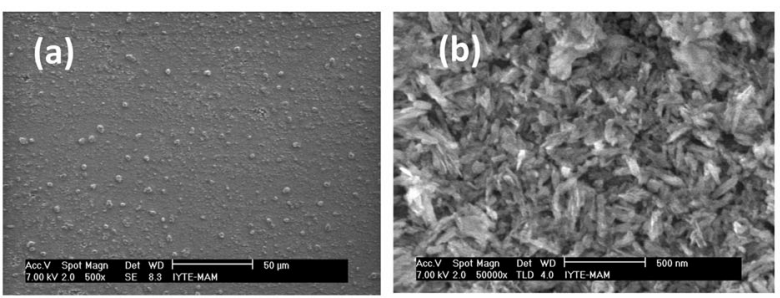

Fig. 1 The SEM images of the c-HAp coatings on the glass substrates prepared by $15 \mathrm{w} \%$ solid content sol by dip coating, at various magnifications (a) 500x, (b) 50,000x, and the m-HAp coatings on the glass
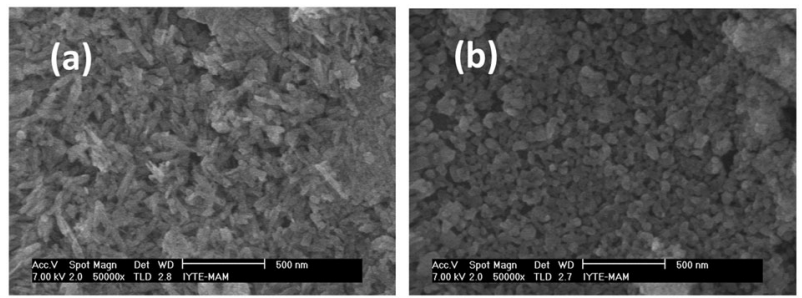

Fig. 2 The SEM images of the thin films prepared with $15 \mathrm{w} \%$ HAp suspensions after the heat treatment at $560{ }^{\circ} \mathrm{C}$, for $30 \mathrm{~min}$. with a heating rate of $15^{\circ} \mathrm{C} / \mathrm{min}$ at various magnifications (a) c-HAp 50,000x, (b) m-HAp 50,000x.

sintering, particles fusing together, could be seen in Fig. 2a, b for c-HAp and m-HAp coatings, respectively.

XRD and FTIR were employed for the characterization of the thin films. The thin film grazing incidence XRD patterns of the c-HAp and m-HAp coatings before, and after the heat treatment at $560{ }^{\circ} \mathrm{C}$ for $30 \mathrm{~min}$ can be found elsewhere [24]. The patterns were identified as hydroxyapatite, the peaks of which superimposed on the broad peak that belonged to the amorphous glass substrate. The major peaks in all of the patterns were at $2 \theta$ values of $32.9,32.2,31.8$, 28.9, 25.9 degrees. The relative intensities of the peaks of c-HAp films at $2 \theta=32.9,32.2,31.8$ degrees were lower, in comparison to m-HAp films. The relative peak intensities of the heat treated $\left(560^{\circ} \mathrm{C}, 30 \mathrm{~min}\right)$ films were slightly higher as compared to their counterparts, which might have been due to crystal size increase. However, heat treatment had no detectable effects on the crystallinity of the hydroxyapatite films, and there were not any phase changes, as can be expected. The chemistry of the c-HAp and the m-HAp surfaces were thus taken as identical [22].

The topographical AFM image for the sericin film on the glass substrate (Fig. 3) showed a granular total surface coverage with the average granular size being in the range of $150-250 \mathrm{~nm}$, and sporadic agglomerates in the range of $400-600 \mathrm{~nm}$. The phase images indicated a homogeneous surface with insignificant agglomeration. This phenomenon is most likely due to an isotropic structure exhibiting thickness differences as can be seen in Fig. 3c.
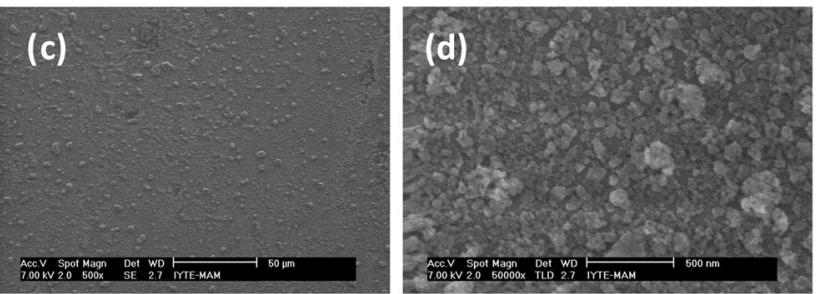

substrates prepared by $15 \mathrm{w} \%$ solid content sol by dip coating at various magnifications (c) 500x, (d) 50,000x.

The AFM image for the fibroin film on glass substrate (Fig. 4) showed that the surface was totally covered with fibroin and with discernable grains of sizes 100-200 nm. The grains tend to align in straight lines reminiscent of fibrous structures. The topographical image showed sporadic lumps of fibroin agglomerates in the range of 400-600 nm while the phase image did not indicate such agglomeration. This again most probably points out to a fluctuating thickness of an isotropic film (Fig. 4c).

These sericin and fibroin coated glasses were used as substrates for the dip coating of $15 \mathrm{w} \%$ solid content suspensions of c-HAp, and m-HAp particulate sols. The minimum threshold solid content of suspensions in order to obtain full surface coverage on the sericin and fibroin layers, was determined to be $15 \mathrm{w} \%$. The films coated on the glass/sericin substrates were totally transparent, while the films coated on the glass/fibroin substrates were slightly opacified.

The SEM and AFM images of the c-HAp and m-HAp films on glass/sericin substrates are shown in Fig. 5. The c-HAp films were decisively more homogeneous as compared to their counterparts coated on the glass substrates. The agglomerate sizes were also less than $300 \mathrm{~nm}$ explaining the visible light transparency of the films. The surfaces were predominantly covered by primary particles, and the thickness of the HAp layer on top of the sericin layer was measured to be 150-200 nm (determined by profile measurements), indicating a film of 3-4 layers of primary particles compaction. The AFM image showed the same homogeneous feature of the films. The agglomerate like structures in the topographical images were most probably due to the fluctuating thickness differences of the intermediate sericin film. The SEM and AFM images of the m-HAp films on glass/sericin substrates again showed that the films were decisively more homogeneous as compared to their counterparts coated on glass substrates. However, the surfaces were covered predominantly by agglomerates, evidencing the increased agglomeration tendency of the higher surface area particles. The films were still visible light transparent since the agglomerate sizes were less than $300 \mathrm{~nm}$. The agglomerates consisted of primary particles 

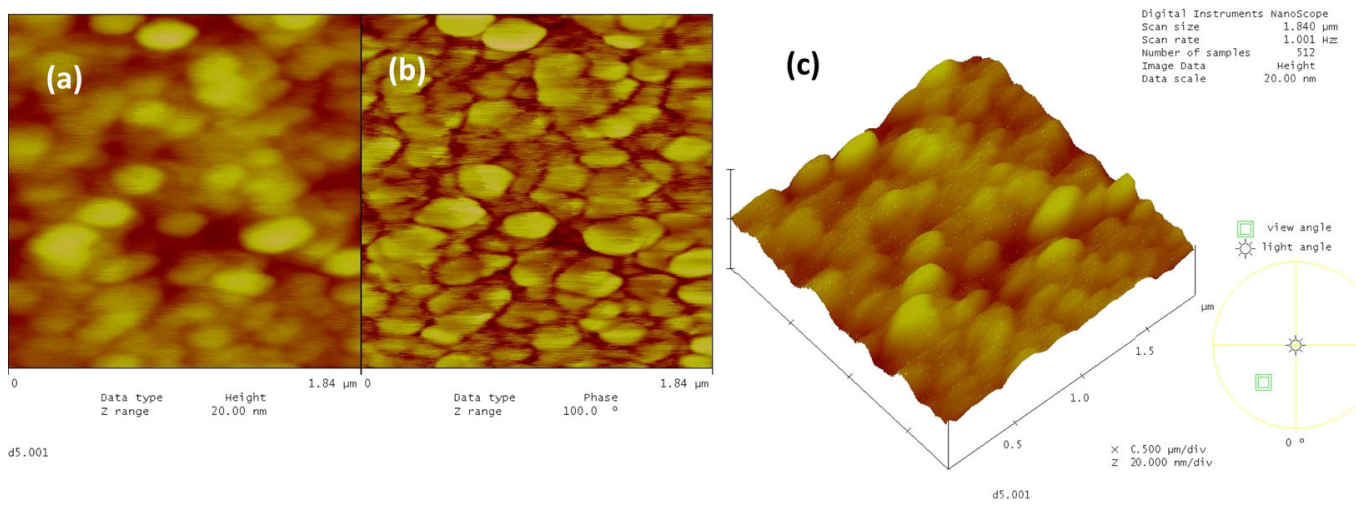

Fig. 3 The AFM images of the sericin film on glass substrate, (a) 2-dim. topographical, (b) phase, and (c) 3-dim. topographical images, 1.84 $\times$ $1.84 \mu \mathrm{m}$.
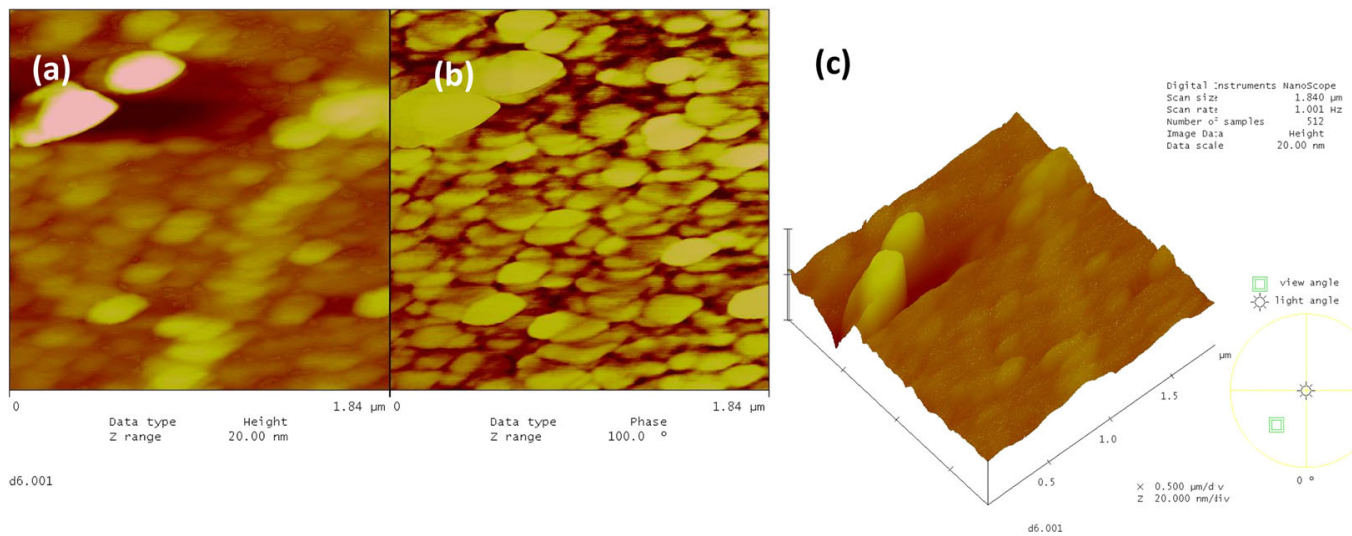

Fig. 4 The AFM images of the fibroin film on glass substrate, (a) 2-dim. topographical, (b) phase, and (c) 3-dim. topographical images, 1.84 $\times$ $1.84 \mu \mathrm{m}$.
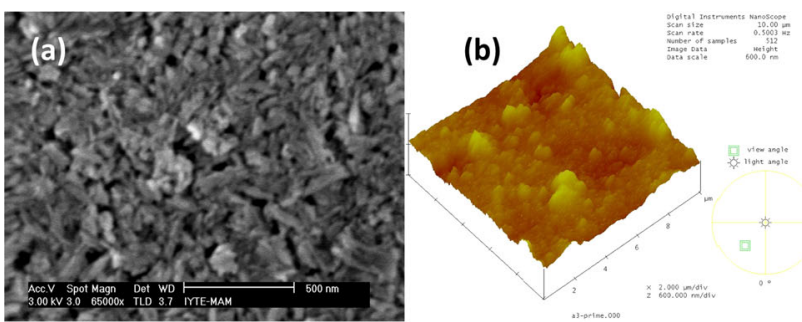

Fig. 5 The SEM and AFM images of the c-HAp and m-HAp films (with $15 \mathrm{w} \%$ solid content suspension) on the glass/sericin substrate (a) the SEM image of c-HAp film, 65,000x, (b) the AFM 3-dim.

with sizes less than $50 \mathrm{~nm}$. The thickness of the HAp layer on top of the sericin layer was measured as $150-200 \mathrm{~nm}$. The AFM image also showed agglomerates as in the SEM images. The highly fluctuating thickness of the sericin film beneath was responsible of the lumps in the topographical image.

The SEM and AFM images of the c-HAp films on glass/ fibroin substrates are shown in Fig. 6. The films were more homogeneous as compared to their counterparts coated on glass substrates. However, the agglomerate sizes were in the
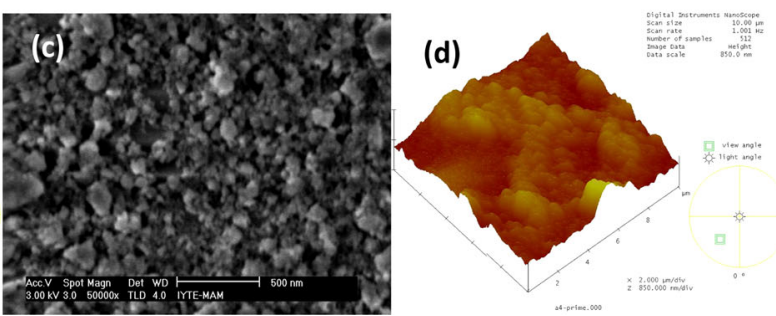

topographical image of c-HAp film, $10 \times 10 \mu \mathrm{m}$, (c) the SEM image of m-HAp film, 50,000x (d) the AFM 3-dim. topographical image of m-HAp film, $10 \times 10 \mu \mathrm{m}$.

range $400 \mathrm{~nm}-1 \mu \mathrm{m}$, and covered $\sim 35 \%$ of the surface, partially reflracting light as well as scattering, which explains the slightly opacified appearance of the films. The thickness of the c-HAp layer on top of the fibroin layer was measured to be $150-200 \mathrm{~nm}$. This again corresponds to a film of 3-4 layers of packed primary particles. The AFM topographic image indicated the same particle and agglomerate features of the films. The thickness fluctuation of the fibroin films $(1-2 \mu \mathrm{m})$ were not so extensive as in the case of sericin films, however, the effect was still visible 

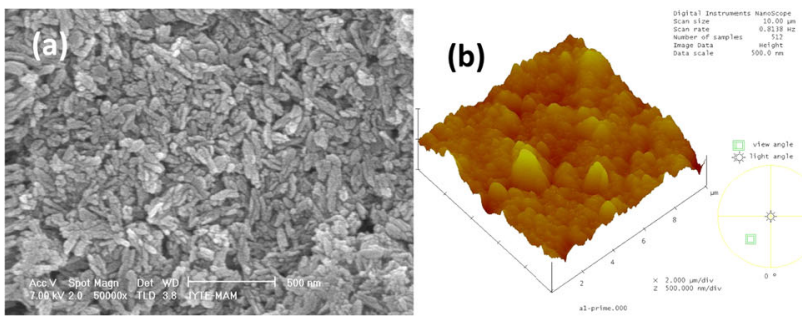

Fig. 6 The SEM and AFM images of the c-HAp and m-HAp films (with $15 \mathrm{w} \%$ solid content suspension) on the glass/fibroin substrate (a) the SEM image of c-HAp film, 50,000x, (b) the AFM 3-dim.

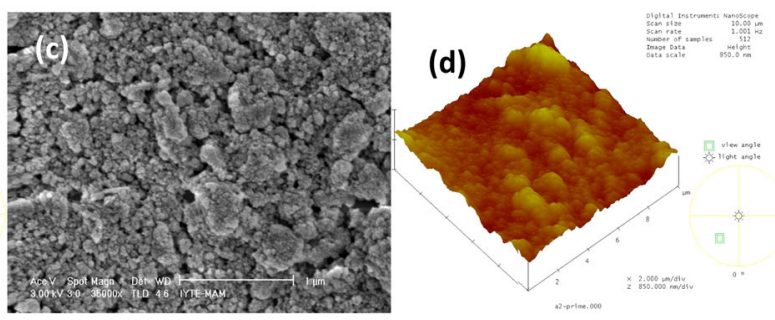

topographical image of c-HAp film, $10 \times 10 \mu \mathrm{m}$, (c) the SEM image of m-HAp film, 35,000x (d) the AFM 3-dim. topographical image of m-HAp film, $10 \times 10 \mu \mathrm{m}$.
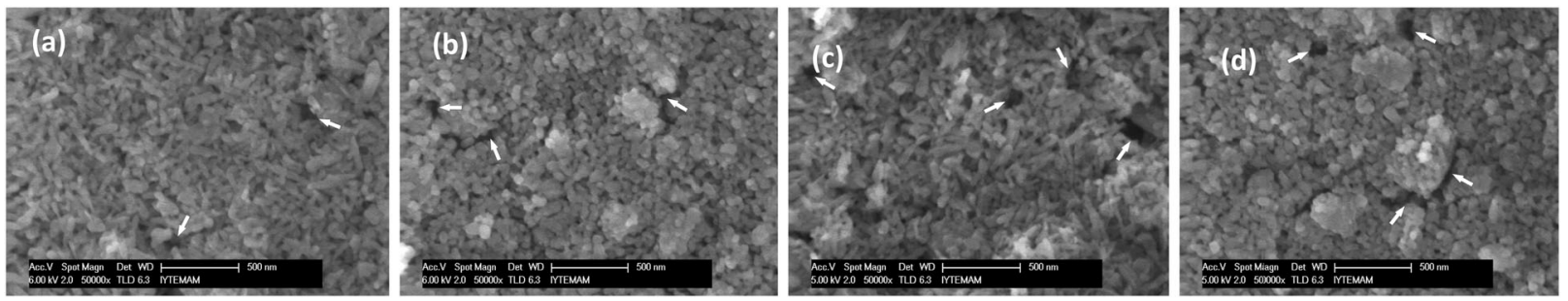

Fig. 7 SEM images of (a) the glass/sericin/c-HAp, (b) the glass/sericin/m-HAp, (c) the glass/fibroin/c-HAp, (d) the glass/fibroin/m -HAp thin film structures after heat treatment at $560{ }^{\circ} \mathrm{C}$; the arrows indicate some of the hole-like gaps through which sericin and fibroin burnt out.

with the agglomerate like structures in the topographical images. The SEM and AFM images of the m-HAp films on glass/fibroin substrates showed that again the films were more homogeneous as compared to their counterparts coated on glass substrates. The maximum agglomerate size was close to $2 \mu \mathrm{m}$, and predominantly the agglomerate sizes were less than $500 \mathrm{~nm}$. The films were again slightly opacified. The thickness of the m-HAp layer on top of the fibroin layer was measured to be $250-600 \mathrm{~nm}$. The AFM topographical image also showed agglomeration with agglomerates dominant in the range $100-500 \mathrm{~nm}$, as in the SEM images. The effect of the variable thickness of the intermediate fibroin film was seen in the topographical images.

The glass/sericin/c-HAp, glass/sericin/m-HAp, glass/ fibroin/c-HAp and glass/fibroin/m-HAp structures were heat treated at $560{ }^{\circ} \mathrm{C}$, for $30 \mathrm{~min}$ with a heating ramp rate of $15^{\circ} \mathrm{C} / \mathrm{min}$, and the effect is shown in Fig. 7. The hydroxyapatite coatings remained intact, and the onset of sintering was apparent especially for the coatings on the sericin layer. The hole-like gaps (some of which are indicated by the arrows) were formed most probably because of the gaseous products evolution during the burning of sericin and fibroin layers.

Apparently, the effect of intermediate sericin and fibroin films was the selective deposition of particles of minimal available sizes, predominantly of the primary particles. The affinity of the spatially recurring carboxyl groups $\left(\mathrm{COO}^{-}\right)$in the $\beta$-sheet structure of silk proteins, for $\mathrm{Ca}^{2+}$ of the hydroxyapatite crystal was reported in the literature; the other possibility that amino groups, $-\mathrm{NH}_{3}{ }^{+}$or $=\mathrm{NH}_{2}{ }^{+}$, to have an affinity for $\mathrm{PO}_{4}{ }^{3-}$ in the hydroxyapatite crystal was considered as a minor effect in comparison to the former because of the polar concentrated arrangement (rather than regular spatial arrangement) of these groups in the $\beta$-sheet protein structure [16-18, 26].

The forces in effect for the hydroxyapatite particle deposition on the silk sericin and fibroin films were the same as adsorption phenomenon. By that token the HAp particle deposition during the thin film formation process was most likely due to the coulombic interaction between the regular arrangement of surface negative charge distribution of sericin and fibroin in the $\beta$-sheet structure provided by the $\mathrm{COO}^{-}$groups, and the recurring positive surface charge site strips rich in $\mathrm{Ca}^{2+}$ on the (100) and (010) faces of hexagonal HAp crystals. On the (001) face of the HAp crystal lattice, 6 oxygen ions that belong to three crystal phosphates create negative charge sites, which may have a coulombic attraction for the polar $-\mathrm{NH}_{3}{ }^{+}$groups in the $\beta$-sheet structure. The former coulombic interaction probably provided a partially positive degree of cooperativity for the HAp particle deposition on the sericin and fibroin surfaces; together with the latter coulombic interaction the degree of cooperativity might change from partially positive to positive [27]. However, the agglomeration tendency between the HAp particles was a factor that reduced the degree of cooperativity.

The thin coatings of essentially primary particles of HAp, with drastically reduced number and size of agglomerates, and homogeneity on the sericin, and the fibroin films were 
Fig. 8 The AFM phase images of adsorbed BSA on (a) glass, (b) glass/c-HAp film (c) glass/ m-HAp film
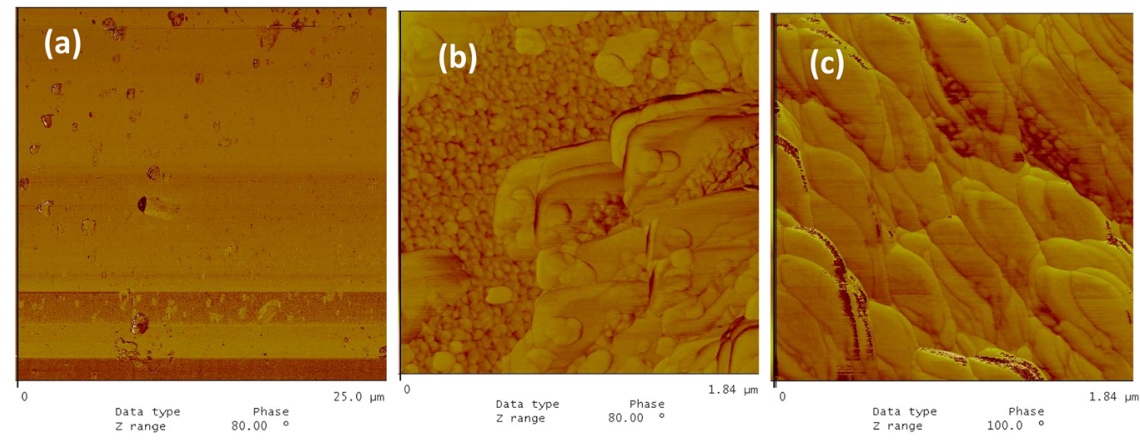

thus resulted from the surface energy minimization of the deposition process driven by coulombic attraction, and probably pointed out to a high degree of positive cooperativity. The agglomeration tendency of the smaller size HAp particles deteriorated the degree of cooperativity, and hence, the surface homogeneity which was visible in the glass/ sericin/m-HAp, and especially glass/fibroin/m-HAp coatings shown in Figs. 5c and 6c, respectively. The coatings with the c-HAp, namely, glass/sericin/c-HAp and glass/ fibroin/c-HAp in Figs. 5a and 6a, respectively, indicated a lower tendency for agglomeration and a more homogeneous film structure, which was most probably the result of a higher degree of positive cooperativity in the deposition.

On the other hand, the HAp coatings on sericin were more homogeneous with less agglomerates of smaller sizes in comparison to the coatings on fibroin as can be seen in Fig. 5a, b, and Fig. 6a, b. This might be due to a more pronounced random coil structure with respect to $\beta$-sheet structure in the fibroin films, and due to an inherent surface charge distribution even in the $\beta$-sheet structure of fibroin reducing the degree of positive cooperativity for HAp deposition. The surface charge distribution regularities are expected to be delimited by the surface topography, and crystal size and shape which were also factors in determining the HAp particle deposition on the sericin and fibroin surfaces.

\subsection{Enhanced model protein adsorption of silk protein/hydroxyapatite thin films}

BSA was used to model the adsorption behavior of bone growth factors or cytokines on the hydroxyapatite coated surfaces. The affinities of BSA, a globular protein, and collagen, a fibrillar protein for the aforementioned film surfaces were investigated by AFM imaging. The effect of an intermediate silk sericin thin layer beneath the hydroxyapatite coatings, on the BSA adsorption, was quantified.

The AFM phase image of the BSA adsorbed on glass is given in Fig. 8a. The glass surface was virtually featureless, and the BSA particles were discernable in both the topological and the phase images as equiaxed particles in accord with the fact that BSA particles are globular [28]. Few BSA particles occupied the glass surface. The AFM phase images of BSA adsorbed on glass/c-HAp and glass/m-HAp films substrates are shown in Fig. 8b, c, respectively. The $1.84 \times$ $1.84 \mu \mathrm{m}$ images illustrated the adsorption of BSA particles of the approximate size range of $20-50 \mathrm{~nm}$. The adsorbed BSA quantity on the glass/m-HAp film was nearly the same as on the glass. However, the quantity adsorbed on the glass/c-HAp film was higher than the previous substrates.

The AFM phase images of the BSA adsorption on fibroin/c-HAp, fibroin/m-HAp, sericin/c-HAp, and sericin/ m-HAp films are shown in Fig. 9. The $1.84 \times 1.84 \mu \mathrm{m}$ phase image, and $1.84 \times 1.84 \mu \mathrm{m}$ 3-dimensional topographical image scans provided the insight. From higher to lower, the adsorption capacities of the films were ranged as sericin/cHAp, fibroin/c-HAp, sericin/m-HAp, and fibroin/m-HAp. The discernable BSA phase indicated that glass/sericin/cHAp and glass/fibroin/c-HAp film structures adsorbed multilayer of BSA particles which was drastically higher than the BSA adsorbed on the glass/sericin/m-HAp and glass/fibroin/m-HAp films, as well as the glass/c-HAp and glass/m-HAp films. On the fibroin/c-HAp film the BSA particles covered the HAp surface with agglomerates of 50-300 nm, while on the fibroin/m-HAp film the surface coverage comprised BSA particles of the size $50 \mathrm{~nm}$ on the average. The multilayer BSA layer adsorbed on the sericin/ c-HAp surface consisted of the BSA particle agglomerates of the sizes ranged in 50-400 nm. The sericin/m-HAp film surface coverage of the BSA was of agglomerate sizes of $35-50 \mathrm{~nm}$.

The glass/sericin/c-HAp provided the best coating for BSA adsorption. The glass/fibroin/c-HAp proved to be the next best for the BSA adsorption. The glass/sericin/m-HAp coating proved to be slightly better than its glass /fibroin/mHAp counterpart for adsorbing BSA. However, the BSA adsorption affinity was drastically lower with the m-HAp films over sericin and fibroin surfaces. This indicated that the adsorbed BSA quantity reduced on the smaller particle size HAp films, glass/m-HAp, glass/fibroin/m-HAp and glass/sericin/m-HAp alike, most probably due to the extensive HAp particle agglomeration disrupting the regular 

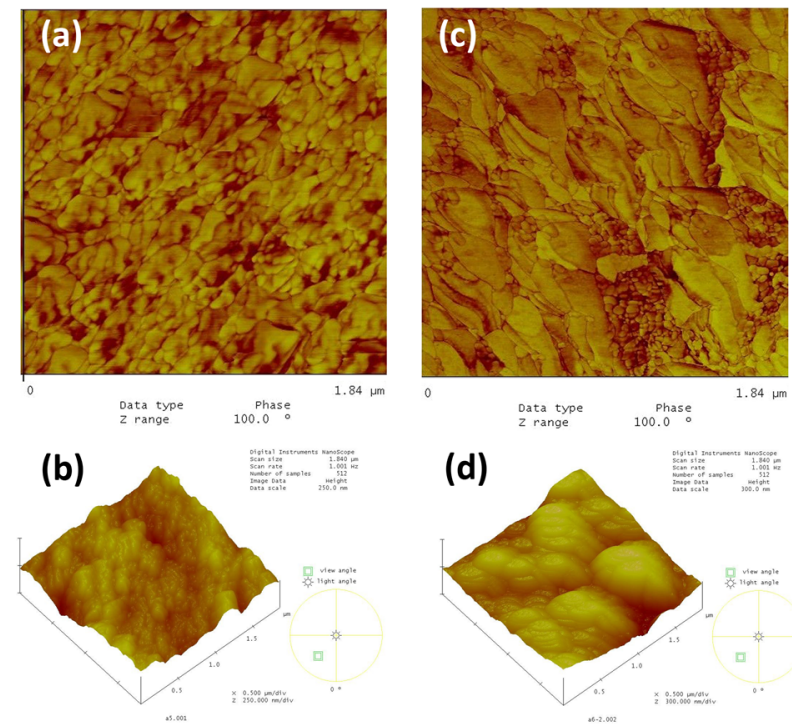

Fig. 9 The AFM images of adsorbed BSA on (a) the glass/fibroin/cHAp; phase image, (b) the glass/fibroin/c-HAp; 3-dim. topographical image, (c) the glass/fibroin/m-HAp; phase image, (d) the glass/fibroin/ m-HAp; 3-dim. topographical image, (e) the glass/sericin/c-HAp;

surface charge distribution. The positive degree of cooperativity in the coulombic attraction driven adsorption process was therefore reduced. The adsorption process of protein molecules was affected by the topographical structure of the surface as well as the chemical structure.

The AFM image of the collagen type I adsorbed on the glass surface is shown in Fig. 10a. The adsorption was negligible. The AFM images of the collagen type I adsorption on c-HAp, and m-HAp films on glass substrates, are given in Fig. 10b, c, respectively. Although on the c-HAp film collagen fibers were very little, on the m-HAp surface there were not any collagen fibers observed.

The collagen type I adsorption on the glass/fibroin/cHAp and glass/fibroin/m-HAp films are given in Fig. 11a, b, respectively. On the c-HAp film the collagen fiber adsorption was extensive with nearly full surface coverage, while on the m-HAp film the surface coverage was very little. The collagen type I adsorption on the glass/sericin/c-HAp, and glass/sericin/m-HAp films are given in Fig. 11c, d, respectively. The collagen coverage of the c-HAp film was roughly half of the surface, evidencing an affinity less than for the glass/fibroin/c-HAp coating. On the m-HAp surface there were no observable collagen fiber adsorption at all. However, near the edge of the film where glass substrate was exposed directly to the collagen suspension little collagen fiber was observed.

These results for the collagen type I fibers indicated that surface topographic structure proves to be an important factor, as well as the chemical structure, determining adsorption affinity. The coatings with the intermediate fibroin layers provided a better adsorption affinity for the
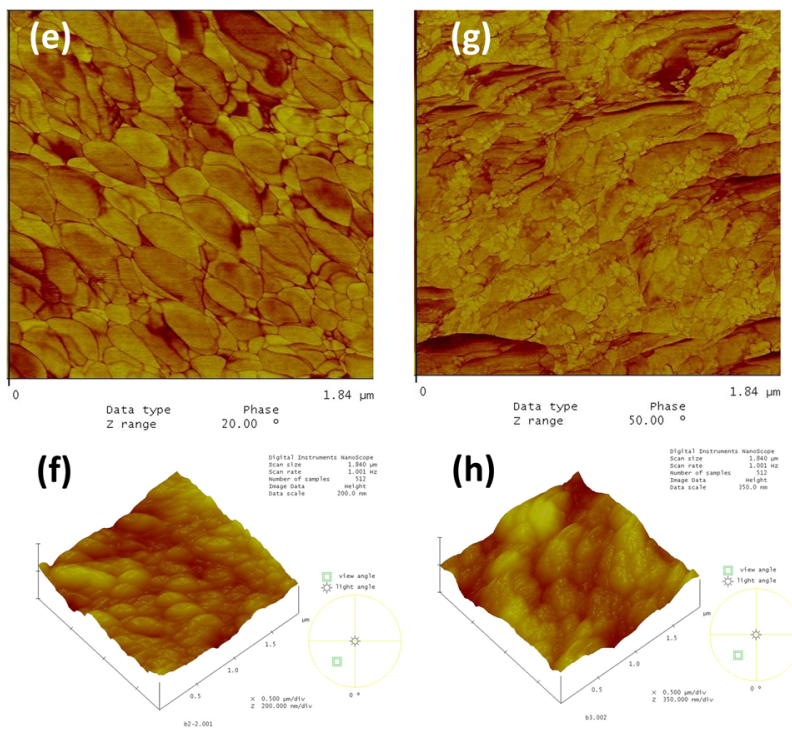

phase image, (f) the glass/sericin/c-HAp; 3-dim. topographical image, (g) the glass/sericin/m-HAp films; phase image, (h) the glass/sericin/ m-HAp films; 3-dim. topographical image.

collagen type I fibers as compared to the coatings with the intermediate sericin layer, a phenomenon which was reverse for that of the BSA adsorption.

The c-HAp particles might have been spatially distributed over the fibroin surface during their deposition, forming a charge distribution complementary and corresponding to that of the fibroin film underneath which might be considered as a template. Therefore, the collagen adsorption was also enhanced on the glass/fibroin/c-HAp coating, because of the matching surface charge of the c-HAp layer distributed in accordance with the fibroin film template. This phenomenon also pointed out that the interaction between the fibroin film and collagen fibers was predominantly coulombic rather than hydrophobic, since the adsorption also enhanced on the c-HAp surface with the intermediate fibroin film acting as a template. The collagen type I fiber adsorptions on the m-HAp surfaces were much lower (or even non-existent) as compared to the c-HAp surfaces.

\subsection{Quantification of the adsorption of BSA on the thin films of c-HAp and m-HAp on glass, and glass/sericin substrates}

The BSA concentrations were measured by the HPLC size exclusion method, with $100 \mathrm{mM}$ PBS solution as the mobile phase. The decrease in the BSA concentration was monitored as a function of time. The $\mathrm{R}^{2}$ equals 0.9915 for the calibration curve obtained for the total BSA including its dimmer. The BSA adsorption on glass, glass/c-HAp, glass/ m-HAp, glass/sericin/c-HAp, glass/sericin/m-HAp was 
Fig. 10 The AFM phase image of adsorbed collagen type I on (a) the glass, (b) the glass/cHAp film, (c) the glass/mHAp film.
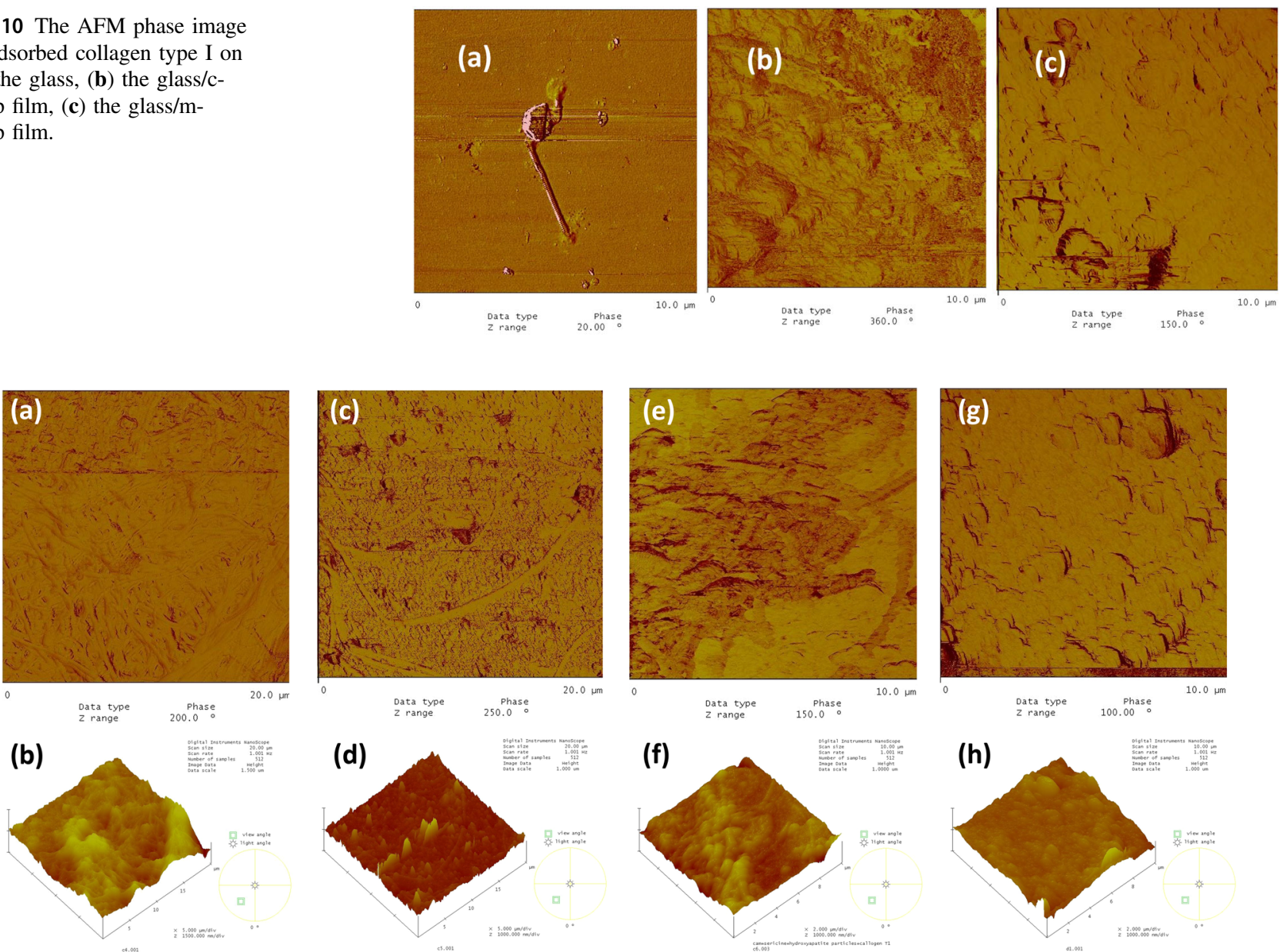

Fig. 11 The AFM images of adsorbed collagen type I on (a). a the glass/fibroin/c-HAp; phase image, (b) the glass/fibroin/c-HAp; 3-dim. topographical image, (c) the glass/fibroin/m-HAp; phase image, (d) the glass/fibroin/m-HAp; 3-dim. topographical image, (e) the glass/sericin/

studied. The change in BSA solution concentration with time is given in Fig. 12. The glass substrates adsorbed BSA as well. The glass/m-HAp film did not show any enhanced adsorption over glass substrates. The BSA adsorption of glass/sericin/m-HAp substrate was nearly the same as glass/ c-HAp substrate. The BSA concentration at 150 min was 9\% lower in comparison to glass substrate (a decrease from $43.8 \mu \mathrm{g} / \mathrm{mL}$ for glass to $39.6 \mu \mathrm{g} / \mathrm{mL}$ for glass $/ \mathrm{c}-\mathrm{HAp}$ ). The largest decrease in BSA concentration was for the glass/sericin/c-HAp film. The difference from glass substrate was around $30 \%(43.8 \mu \mathrm{g} / \mathrm{mL}$ for glass, $33.6 \mu \mathrm{g} / \mathrm{mL}$ for glass/sericin/c-HAp film) at $150 \mathrm{~min}$. Therefore, the adsorption of BSA on glass/sericin/c-HAp film was the highest, a phenomenon supported by the AFM imaging results. Another feature of the adsorption curve was in that the time rate of concentration was fast until 20 min after which it slowed down or even flattened.

The adsorbed quantities per unit area are given in Fig. 13. For the glass/c-HAp and glass/sericin/m-HAp films, the
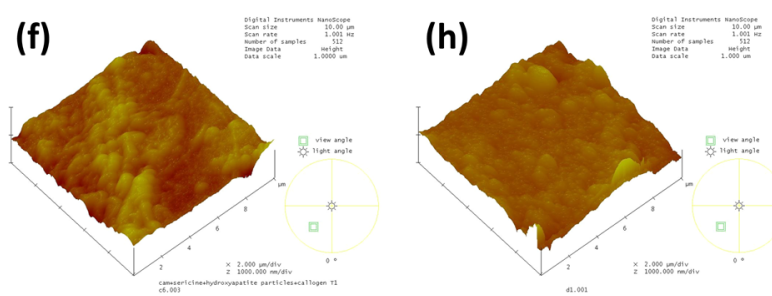

c-HAp; phase image, (f) the glass/sericin/c-HAp; 3-dim. topographical image, (g) the glass/sericin/m-HAp films; phase image, (h) the glass/ sericin/m-HAp films; 3-dim. topographical image.

maximum adsorption was around $1 \mu \mathrm{g} / \mathrm{cm}^{2}$ and there was a tendency for the adsorbed amount to decrease at elongated times. The maximum adsorption of BSA was on glass/sericin/c-HAp film, $2.6 \mu \mathrm{g} / \mathrm{cm}^{2}$, a result evidencing the effectiveness of surface topographical structure as well as the chemical structure for BSA adsorption on hydroxyapatite surfaces.

\section{Discussion}

The purpose of this work was to prepare hydroxyapatite/silk protein thin film implant surfaces by a particulate sol-gel method, and to investigate their microstructural properties and model protein interactions for enhanced osteoinduction. By the SEM and AFM images, the minimum solid ratio of the suspensions was determined to be $15 \%$ for complete surface coverage of the glass substrates coated with c-HAp powder suspension; with the same solid ratio $~ 90 \%$ of the 
Fig. 12 The BSA adsorption on glass (blank), glass/c-HAp, glass/m-HAp, glass/sericin/cHAp, and glass/sericin/m-HAp substrates, reported as decrease in BSA concentration versus contact time.

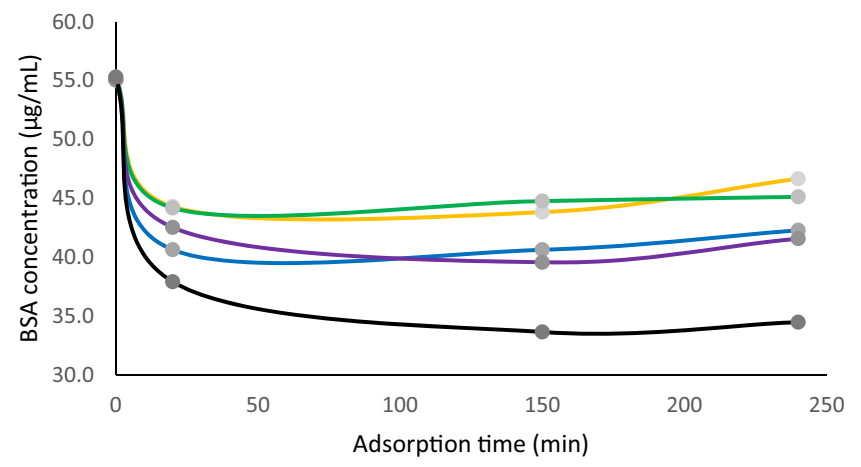

- - Glass

- Glass/m-HAp

- - Glass/sericin/m-HAp

- - Glass/c-HAp

- Glass/sericin/c-HAp

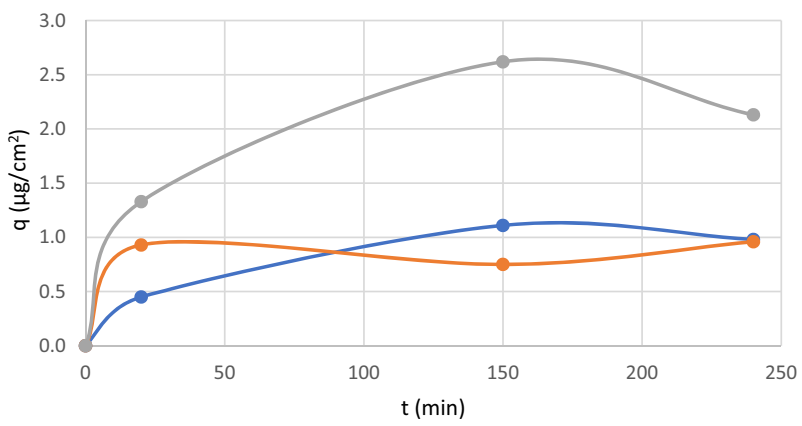

$\longrightarrow$ glass/c-HAp $\longrightarrow$ glass/sericin/m-HAp $\longrightarrow$ glass/sericin/c-HAp

Fig. 13 BSA adsorbed quantity as a function of time on the glass/cHAp, the glass/sericin/m-HAp, and the glass/sericin/c-HAp films.

substrate surfaces were coated with the m-HAp powder suspension. The c-HAp films on glass/sericin substrates were decisively more homogeneous as compared to their counterparts coated on glass substrates. Approximately 85\% of the surface was covered with primary particles, and the agglomerate sizes were also less than $300 \mathrm{~nm}$ explaining the visible light transparency of the films. The thickness of the c-HAp layer on top of the sericin layer was measured to be 150-200 nm. The m-HAp films on glass/sericin substrates were also more homogeneous as compared to glass substrates. The surface was covered predominantly by agglomerates, however, less than $400 \mathrm{~nm}$ in size, evidencing the increased agglomeration tendency of the higher surface area particles, compared to c-HAp. Still the films were visible light transparent. The thickness of the m-HAp layer on top of the sericin layer was 150-200 nm. For both the c-HAp and the m-HAp films on glass/fibroin substrates the films were more homogeneous compared to glass substrates, and slightly scattered light with the predominant aggregate sizes of $400-500 \mathrm{~nm}$; the maximum aggregate sizes reached 1-2 $\mu \mathrm{m}$. The thickness of the c-HAp layer on glass/fibroin substrates were 150-200 nm, while m-HAp layer on the glass/fibroin substrate was $250-600 \mathrm{~nm}$.

Apparently, the effect of intermediate sericin and fibroin films was the selective deposition of primary HAp particles with a certain crystal orientation. The regular arrangement of the carboxyl groups protruding from the $\beta$-sheet surfaces of the silk proteins provided a surface potential distribution that electrostatically bound $\mathrm{Ca}^{2+}$. The regularity was expected to be delimited by the surface topography, and crystal size and shape could also be factors in determining the particle packing on the surface. The high affinity of the silk proteins for BSA and collagen type I were confirmed by AFM imaging. The glass/sericin/c-HAp provided the best layered film for BSA adsorption. Glass/fibroin/c-HAp proved to be the next best for the BSA adsorption. The sericin film underlying the c-HAp proved to be slightly better than its fibroin counterpart for adsorbing BSA. However, the BSA adsorption affinity was found to be drastically lower with the m-HAp films over sericin and fibroin surfaces. The BSA adsorption was quantified by the HPLC analysis. For the glass/c-HAp and glass/sericin/mHAp films, the maximum adsorption was around $1 \mu \mathrm{g} / \mathrm{cm}^{2}$. The maximum adsorption of BSA was on glass/sericin/cHAp film, $2.6 \mu \mathrm{g} / \mathrm{cm}^{2}$, a 2.5 fold increase over unoriented crystal films, a result evidencing the effectiveness of surface topographical structure as well as the chemical structure [29]. Likewise, collagen type I adsorption was drastically lower on the glass/sericin/m-HAp and glass/fibroin/m-HAp films compared to glass/sericin/c-HAp and glass/fibroin/cHAp films. Again, indicating the surface topography to be effective on the protein adsorption affinity of the HAp films.

A regular surface charge distribution of the adsorbent (HAp) induces cooperative adsorption of the flexible BSA molecule [27]. The SEM and AFM images of the HAp coatings indicated much less agglomeration on the intermediate sericin films. The agglomeration is a factor that increases surface roughness and disrupts the regularity of surface charge zones, which in turn reduces the degree of cooperativity for coulombic attraction driven adsorption. The flexible structure, and charged side groups of BSA, together with the regular surface charge strips of the adsorbent HAp surface most probably provided a positive degree of cooperativity in adsorption and the adsorbed quantity of BSA increased when the surface topography was facilitating. This phenomenon was supported by the work of Santos, et al. [22], in which the nano topography of 
calcium phosphates (HAp, and $\beta$-TCP) strongly affected the protein adsorption (serum albumin), being more important than the surface chemistry. Similar results were obtained by them showing that albumin adsorption increased $\sim 5$ fold on a surface with a roughness of $32 \pm 6 \mathrm{~nm}$ in comparison to a rougher surface of identical chemistry with surface roughness $142 \pm 24 \mathrm{~nm}$ [22]. The charge distributions and surface topographical structures of the adsorbate and the adsorbent have to match for enhanced adsorption. A particularly oriented crystalline hydroxyapatite surface was also reported to assist certain biological functions [30, 31].

The first structure that is formed during peri-implant healing is the cementline which biochemically requires adsorbed growth factors on the implant surface, and mechanically requires a stable surface with micron scale roughness or porosity with nanoscale undercuts, reinforced with collagen fibers with which it can interdigitate and interlock for a strong adhesion. The subsequent anchorage and growth of bone tissue on the cementline is also accelerated by the availability of the growth factors on the healing site [5]. Specifically synthesized hydroxyapatite was studied for drug loading and delivery [32]. It was shown that layered structures prepared such as $\mathrm{TiO}_{2}$ /fluorohydroxyapatite/hydroxyapatite increased osteoblast cell proliferation in-vitro for orthopedic and dental implantation [33], and efforts existed to fabricate coatings for controlled drug delivery for faster healing and patient comfort, by solgel methods [34]. In this study, it was shown that c-HAp films on the intermediate fibroin and sericin layers had enhanced adsorption affinity for the collagen type I and BSA, respectively. This indicates that such structures may greatly enhance the in vivo adsorption of collagen fibrils and growth factors on the implant surfaces and provide a very convenient surface at the peri-implant healing site for osteoinduction and osteoconduction, facilitating the formation of an initial cementline interdigitating and interlocking with the implant surface and the subsequent development of an anchored bone tissue. Also, for accelerated healing the implant surfaces can be loaded with the convenient growth factors before implantation for in vivo delivery of these proteins.

\section{Conclusions}

The high affinity of the silk proteins for BSA and collagen type I were confirmed by AFM imaging. The glass/sericin/ c-HAp provided the best layered film for BSA adsorption. Glass/fibroin/c-HAp proved to be the next best for the BSA adsorption. The sericin film underlying the c-HAp proved to be slightly better than its fibroin counterpart for adsorbing BSA. However, the BSA adsorption affinity was found to be drastically lower with the m-HAp films over sericin and fibroin surfaces. The BSA adsorption was quantified by the HPLC analysis. For the glass/m-HAp and glass/sericin/m-HAp films, the maximum adsorption was around $1 \mu \mathrm{g} / \mathrm{cm}^{2}$. The maximum adsorption of BSA was on glass $/$ sericin $/ \mathrm{c}-\mathrm{HAp}$ film, $2.6 \mu \mathrm{g} / \mathrm{cm}^{2}$, a result evidencing the effectiveness of surface topographical structure as well as the chemical structure. Likewise, collagen type I adsorption was drastically lower on the glass/sericin/mHAp and glass/fibroin/m-HAp films compared to glass/ sericin/c-HAp and glass/fibroin/c-HAp films. Again, indicating the surface topography to be effective on the protein adsorption affinity of the HAp films. The study implies that if bone morphogenetic proteins (BMPs) are loaded prior to implantation, or by the ability of the coated implant surface to adsorb the growth factors and cytokines in vivo, this will signal the migration, attachment, and differentiation of the pluripotent stem cells accelerating the peri implant healing process.

\section{Compliance with ethical standards}

Conflict of interest The authors declare no competing interests.

Publisher's note Springer Nature remains neutral with regard to jurisdictional claims in published maps and institutional affiliations.

Open Access This article is licensed under a Creative Commons Attribution 4.0 International License, which permits use, sharing, adaptation, distribution and reproduction in any medium or format, as long as you give appropriate credit to the original author(s) and the source, provide a link to the Creative Commons license, and indicate if changes were made. The images or other third party material in this article are included in the article's Creative Commons license, unless indicated otherwise in a credit line to the material. If material is not included in the article's Creative Commons license and your intended use is not permitted by statutory regulation or exceeds the permitted use, you will need to obtain permission directly from the copyright holder. To view a copy of this license, visit http://creativecommons. org/licenses/by/4.0/.

\section{References}

1. Guyton AC. Textbook of medical physiology. 8th ed. Philadelphia: W. B. Saunders Company; 1991. Chapter. 79

2. Winn SR, Uludag H, Hollinger JO. Sustained release emphasizing recombinant human bone morphogenetic protein-2. Adv Drug Deliv Rev. 1998;31:303-18.

3. Hench LL. Bioceramics. J Am Ceram Soc. 1998;81:1705-28.

4. Albrektsson T, Johansson C. Osteoinduction, osteoconduction and osseointegration. Eur Spine J. 2001;10:S96-101.

5. Davies JE, Hosseini MM. Histodynamics of endosseous wound healing. Davies JE. editor, Chapter 1: 1-14, Bone Engineering. Toronto: Em Squared Inc.; 2000.

6. Jaafar A, Hecker C, Arki P, Joseph Y. Sol-gel derived hydroxyapatite coatings for titanium implants: a review. Bioengineering. 2020;7:127. https://doi.org/10.3390/bioengineering7040127.

7. Heimann RB. Thermal spraying of biomaterials. Surf Coat Technol. 2006;201:2012-9. 
8. Best SM, Porter EA, Thian ES, Huang J. Bioceramics: past, present and for the future. J Eur Ceram Soc. 2008;28:1319-27.

9. Radin SR, Ducheyne P. Plasma spraying induced changes of calcium phosphate ceramic characteristics and the effect on in vitro stability. J Mater Sci: Mater Med. 1992;3:33-42.

10. Cirilli F, Kaciulis S, Mattogno G, Righini G, Ferrari F. Surface analysis of biocompatible hydroxyapatite coatings on titanium. Olefjord J., Nyborg L., Briggs D, editors. Chichester: John Wiley and Sons. ECASIA. 1997;97:151-4.

11. Muller V, Pagnier T, Tadier S, Gremillard L, Jobbagy M, Djurado E. Design of advanced one-step hydroxyapatite coatings for biomedical applications using the electrostatic spray deposition. Applied Surface Science 0169-4332/ $/^{\circledR} 2020$ Elsevier B.V. https:// doi.org/10.1016/j.apsusc.2020.148462.

12. Moskalewicz T, Warcaba M, Cieniek L, Sitarz M, Gajewska M, Boccaccini AR. Hydroxyapatite/sodium alginate coatings electrophoretically deposited on titanium substrates: microstructure and properties. Applied Surface Science 0169-4332/ ${ }^{\odot} 2020$ Elsevier B.V. https://doi.org/10.1016/j.apsusc.2020.148353.

13. Kim H-W, Knowles JC, Salih V, Kim H-E. Hydroxyapatite and fluor-hydroxyapatite layered film on titanium processed by a solgel route for hard tissue implants. J Biomed Mater Res Part B: Appl Biomater. 2004;71B:66-76.

14. Gan L, Pilliar R. Calcium phosphate sol-gel derived thin films on porous-surfaced implants for enhanced osteoconductivity Part I: Synthesis and characterization. Biomaterials. 2004;25:5303-12.

15. Cavalli M, Gnappi G, Montenero A, Bersani D, Lottici PP, Kaciuli S, et al. Hydroxy and fluorapatite films on Ti Alloy substrates: Sol-gel preparation and characterization. J Mater Sci. 2001;36:3253-60.

16. Kong XD, Sun X, Cui F, Ma C. Effect of solute concentration on fibroin regulated biomineralization of calcium phosphate. Mater Sci Eng C. 2006;26:639-43.

17. Takeuchi A, Othsuki C, Miyazaki T, Kamitakahara M, Ogata S, Yamazaki M, et al. Heterogeneous nucleation of hydroxyapatite on protein: structural effect of silk sericin. J R Soc Interface. 2005;2:373-8.

18. Altman GH, Diaz F, Jakuba J, Calabro T, Horan RL, Chen J, et al. Silk-based biomaterials. Biomaterials. 2003;24:401-16.

19. Kunz RI, Brancalhao RMC, Ribeiro LFC, Natali MRM. Silkworm sericin: properties and biomedical applications. BioMed Res Int. 2016;16:19. https://doi.org/10.1155/2016/8175701.

20. Bansal G, Wright JE, Zhang S, Zernicke RF, Uludag H. Imparting mineral affinity to proteins with thiol-labile disulfide linkages. J Biomed Mater Res Part A. 2005;74A:618-28.

21. Kandori K, Fujiwara A, Mukai M, Yasukawa A, Ishikawa T. Evaluation of the adsorption affinity of proteins to calcium hydroxyapatite by desorption and pre-adsorption methods. Colloids Surf B: Biointerfaces. 1998;11:313-20.

22. Santos EA, Farina M, Soares GA. Surface energy of hydroxyapatite and $\beta$-tricalcium phosphate ceramics driving serum protein adsorption and osteoblast adhesion. J Mater Sci: Mater Med. 2008;19:2307-16.

23. Sharafipour M, Oveisi H, Meshkini A. Meso-macroporous crackfree nanohydroxyapatite coatings templated by $\mathrm{C} 12 \mathrm{E} 10$ diblock copolymer on Ti6Al4V implant materials toward human osteoblast-like cells. J Biomed Mater Res Part A. 2020;108:882-94.

24. Ozcan S, Ciftcioglu M. Particulate sol route hydroxyapatite thin film-silk protein interface interactions. Gazi Univ J Sci. 2010;23:475-85.

25. Ajisawa A. Dissolution of silk fibroin with calcium chloride/ ethanol aqueous solution. J Sericultural Sci Jpn. 1998;67:91-4.

26. Kong XD, Cui F, Wang XM, Zhang M, Zhang W. Silk fibroin regulated mineralization of hydroxyapatite nanocrystals. J Cryst Growth. 2004;270:197-202.

27. Luo Q, Andrade JD. Cooperative adsorption of proteins on hydroxyapatite. J Colloid Interface Sci. 1998;200:104-13.

28. Ying $\mathrm{P}, \mathrm{Yu} \mathrm{Y}$, Jin $\mathrm{G}$, Tao Z. Competitive protein adsorption studied with atomic force microscopy and imaging ellipsometry. Colloids Surf B: Biointerfaces. 2003;32:1-10.

29. Ozcan S, Acikbas G, Calis, Acikbas N. Induced superhydrophobic and antimicrobial character of zinc metal modified ceramic wall tile surfaces. Appl Surf Sci. 2018;438:136-46.

30. Inoue K, Sassa K, Yokogawa Y, Sakka Y, Okido M, Asai S. Control of crystal orientation of hydroxyapatite by imposition of a high magnetic field. Mater Trans. 2003;44:1133-7.

31. Rincón-López JA, Hermann-Muñoz JA, Cinca-Luis N, GarridoDomiguez B, García-Cano I, Guilemany-Casadamon JM, et al. Preferred growth orientation of apatite crystals on biological hydroxyapatite enriched with bioactive glass: a biomimetic behavior. Cryst Growth Des. 2019;19:5005-18.

32. Fang $\mathrm{CH}$, Lin YW, Yang CC, Thacker M, Jakfer S, Lin FH. Characterization and evaluation of porous hydroxyapatite synthesized by oil-in-water method as carrier of donepezil for the preventive of Alzheimer's disease by controlled release. J Asian Ceram Societies. 2020;8:1216-27.

33. He G, Guo B, Wang H, Liang C, Ye L, Lin Y, et al. Surface characterization and osteoblast response to a functionally graded hydroxyapatite/fluoro-hydroxyapatite/titanium oxide coating on titanium surface by sol-gel method. Cell Prolif. 2014;47:258-66.

34. Sengottuvelan A, Mederer M, Boccaccini AR. Preparation and characterization of mesoporous calcium-doped silica-coated $\mathrm{TiO}_{2}$ scaffolds and their drug releasing behavior. Appl Ceram Technol. 2018;15:892-902. 